\title{
Practice patterns in transitioning patients from chronic kidney disease to dialysis: a survey of United States nephrologists
}

\author{
Mary C. Mallappallil ${ }^{1 *} \mathbb{D}$, Steven Fishbane ${ }^{2}$, Rimda Wanchoo ${ }^{2}$, Edgar Lerma ${ }^{3}$, Andrea Roche-Recinos ${ }^{1}$ and Moro Salifu'
}

\begin{abstract}
Background: There are no guidelines for transitioning patients from chronic kidney disease stage 5 to hemodialysis. We conducted this study to determine if there are uniform patterns in how nephrologists transition patients to dialysis.

Methods: We designed an electronic survey with 39 questions and sent it to a database of practicing nephrologists at the National Kidney Foundation. Factors that were important for transitioning a patient to hemodialysis were evaluated, including medication changes on dialysis initiation, dry weight and dialysis prescription.

Results: 160 US Nephrologists replied to the survey; 18\% (29/160) of the responses were completed via social media sites. Prior to dialysis, 74\% (118/160), prescribed furosemide and 67\% (107/160) used furosemide with metolazone. Once dialysis started, only $46 \%$ (74/160) of the responders continued patients on diuretics daily. Hypertension medications prescribed in dialysis were calcium channel blockers 69\% (112/160), beta blockers 36\% (58/160), angiotensin converting enzyme inhibitor 32\% (53/160), angiotensin receptor blocker 29\% (46/160) and diuretics 25\% (42/160). Once dialysis started, 68\% (109/160) routinely changed medications. Most, 67\% (107/160) ordered patients to avoid anti-hypertensive medications on dialysis days to allow for ultrafiltration. Dry weight was determined in the first week by $29 \%$ (46/160) and in the first month by 53\% (85/160). Most, 59\% (94/160) felt that multiple causes lead to hypertension. Most nephrologists would prescribe small dialyzers and a shorter period of time for the first dialysis session.
\end{abstract}

Conclusion: The transition period to chronic hemodialysis has variations in practice patterns and may benefit from further studies to optimize clinical practice.

Keywords: Blood pressure, Chronic kidney disease, Diuretic, Hemodialysis, Medication reconciliation, Nephrologist

\section{Background}

According to the United States Renal Data System (USRDS), at the end of 2013 there were 661,648 prevalent patients with End Stage Renal Disease (ESRD); the unadjusted prevalence was 2034 per million in the U.S. population [1]. The first year after the initiation of hemodialysis (HD) is associated with increased mortality. The first 90 days has the highest risk which may be related to multiple causes [2]. Patterns from the Dialysis Outcomes and Practice Study reported the causes for mortality as cardiovascular disease (CVD), followed by withdrawal

\footnotetext{
* Correspondence: marynephrology@aol.com

${ }^{1}$ Division of Nephrology, State University of New York at Downstate, 450

Clarkson Avenue, Box 52, Brooklyn, New York 11203, USA

Full list of author information is available at the end of the article
}

from dialysis; other factors include older age, catheter vascular access issues, albumin $<3.5 \mathrm{~g} / \mathrm{dL}$, phosphorus $<3.5 \mathrm{mg} / \mathrm{dL}$, cancer and congestive heart failure (CHF) [3]. There is limited information about the practices related to the initiation of $\mathrm{HD}$, which requires many clinical decisions and most of the literature is focused on the timing of initiation of HD.

Major contributors to CVD morbidity include hypertension and volume overload. There is little information about the ideal blood pressure (BP) in HD patients due to exclusion of this population in clinical trials; for example the trial of intensive versus standard blood pressure control, with a total of 9361 participants, of which 2646 had early chronic kidney disease (CKD) had no subjects who were on HD at the start of the

(c) The Author(s). 2018 Open Access This article is distributed under the terms of the Creative Commons Attribution 4.0 International License (http://creativecommons.org/licenses/by/4.0/), which permits unrestricted use, distribution, and 
study [4]. At present, the ideal blood pressure in a HD patients remains unclear and without defined BP targets [5-7] [https://www.kidney.org/sites/default/files/KDOQIClinical-Practice-Guideline-Hemodialysis-Update_PublicReview-Draft-FINAL_20150204.pdf] [8].

Multiple therapies including the attaining the correct dry weight, fluid and sodium restriction and medications to achieve BP control have been suggested [9-12]. Benefits of loop diuretics in HD patients include lower inter-dialytic weight gain, a lower odds of hyperkalemia, decrease in all cause and CVD mortality [13]. The benefits of renin angiotensin (RAS) blockade for CVD risk reduction is known, however, the data among HD patients is less certain [14]. A risk of combining both ACEI and ARB in HD that has been reported is an increase in both thirst and inter-dialytic fluid gain, while the variable risk of hyperkalemia was noted when RAS blockage was used [15-17]. Given the diverse findings, it is not surprising that a recent study noted that anti-hypertensive (anti-HTN) medications may be under-utilized in patients- once HD is initiated [18]. As there is no universally accepted technique to determine dry weight, the imprecise technique of altering the ultrafiltration goal aided by BP is used to attain volume control [19]. In the transition period it is unclear when the first dry weight should be determined.

The literature about the initial HD prescription with a shorter duration, lower blood flow and a smaller dialyzer to avoid disequilibrium is limited and comes from animal studies and case reports due to the difficulty of conducting such a trial in humans [20-22].

There is no uniform approach to adjust BP medications, diuretics or dry weight when a patient is started on HD. There is also no clear consensus regarding details on the initiation, the length of time of the first treatment blood flow and dialyzer to be used in HD. This study is designed to understand practice patterns in nephrologists with the goal of filling in the knowledge gaps in this area.

\section{Methods}

We designed an electronic survey with 39 questions and sent it to a United States database of practicing nephrologists at the National Kidney Foundation (NKF). The survey was developed after a comprehensive literature search of the PubMed database on decisions about medication adjustments in early HD, initial HD prescription, volume and $\mathrm{BP}$ control in the HD treatment, failed to show clear evidence on clinical practice patterns. A data abstraction instrument with 39 questions in 7 domains including demographic, BP medication adjustment including ACE-I and ARB use, diuretic use, first HD prescription, access use, other modality use and presence of an ESRD educator was created. The questionnaire was validated prior to being sent out in a pilot test to a panel of 15 practicing nephrologist from multiple sites, including national experts in the field of transitioning patients from CKD to HD. The survey was modified based on the response process from this panel to ensure clarity of the questions.

The anonymous questionnaire is shown in Additional file 1 which is in the supplementary material. Institutional Review Board (IRB) approval was obtained from SUNY Downstate at Brooklyn. The survey was sent out via secured hyperlink (www.surveymonkey.com) twice by the NKF to its membership. An information sheet which explained the survey rationale and author contact information was attached to the questionnaire. Request to do the survey were posted on Facebook and Twitter. The survey was a voluntary without any remuneration for participation. The collected data was kept anonymous and aggregate data was analyzed using descriptive statistics, avoiding duplicate responses. Responses were in the form of single best choice; comparative situations and ranking. The sample frame was practicing US nephrologists and the response rate $(<5 \%)$ was in the range of other nephrology surveys [23]. No data was collected from the non-responders. Responses were collected between March 2015 and March 2016.

\section{Statistical analysis}

The survey was conducted using Surveymonkey. All responses were via its secure link and all responses were available on its site as both individual anonymous and aggregate data. Electronic mail manager ensured no duplication of the survey from individuals. The survey had binary questions (more than/less than; yes/no) in addition to ranking scales (preferred choice with ranking 1 being the highest). The electronic questionnaire had multiple scroll-down pages that were easy to read with clear font. The survey had some questions where multiple options could be selected resulting in cumulative response rates exceeding $100 \%$. Other questions had options to select from alternative mutually exclusive choices. Ranking was used to determine what was degrees of importance including "yes, likely, unlikely, no" and on a numeral scale to determine position of preferences. These questions enabled the computer algorithm to assign a unique weight for each choice. When data was summarized with descriptive statistics, it was described as weighted averages and as percentages.

\section{Results}

Participants and their settings: Surveys were sent to members in the US-NKF nephrologist's database in March 2015 and repeated again. The response rate was 160/5000 and responses were collected until March 2016. Eighteen percent $(28 / 160)$ of the surveys that were completed, were in response to request placed on social media (Facebook and Twitter). Among the 160 responses, most 60\% (96/160) were in practice for more than 10 years. Social media 
platforms were used by 28 nephrologist of whom 75\% $(19 / 28)$ were in practice for more than 10 years.

Among responders, 50\% (80/160) started patients on HD in both inpatient or outpatient settings, where as $29 \%(46 / 160)$ reported starting patients on dialysis in the out-patient setting alone and 21\% (34/160) reported that first dialysis in the hospital setting alone.

\section{Diuretic use}

Asked about diuretic use the majority of the respondents $74 \%(118 / 160)$ reported using furosemide in CKD5 and $67 \%(107 / 160)$ reported using a combination of furosemide with metolazone. Multiple selections were allowed and choices were not mutually exclusive. Once HD had been started, $46 \%(74 / 160)$ of respondents continued to prescribe diuretics daily; $31 \%(50 / 160)$ ordered their use on non-HD days only and 22\% (35/160) stopped the use of diuretics altogether. When asked about the use of spironolactone, $48 \%$ (77/160) of respondents reported that it was continued even after the initiation of HD (Table 1).

\section{Anti-hypertensive effectiveness}

Participants were asked about the most effective medications to control BP control in $\mathrm{HD}$ and the timing of the medications. The majority 69\% (110/160) of the respondents considered calcium channel blockers to be the most effective; $34 \%(54 / 160)$ of them prescribed nifedipine and $35 \%(56 / 160)$ of them administered amlodipine. Beta blockers were reported to be effective by $36 \%(58 / 160)$; ACEI by $32 \%$ (51/160); ARB by $29 \%$ (46/160) and diuretics by $25 \%(40 / 160)$ (Table 2$)$.

When asked what percentage of their HD patients are using ACEI/ARBs, 51\% (82/160) of the respondents reported between 30 to $60 \%$ (Table 3 ). When asked what factors were important in controlling BP in a patient on HD, 49\% (78/160) responded that it was volume, 18\% (29/160) replied that pre-existing HTN was important and $9 \%(13 / 160)$ replied that cardiac function was most important; the majority 59\% (94/160) agreed it was a combination of factors that allow BP control.

Table 1 Use of diuretics when transitioning a patient to hemodialysis

\begin{tabular}{ll}
\hline Diuretic use in CKD5 & Total $N=160$ \\
Furosemide & 118 \\
Furosemide with metolazone & 107 \\
Diuretic use in CKD5-D & \\
Daily use once HD started & 74 \\
Non-HD day use & 50 \\
Stop diuretic when HD started & 35 \\
\hline
\end{tabular}

CKD 5 = chronic kidney disease stage $5, H D=$ hemodialysis
Table 2 Use of BP medications when transitioning a patient to hemodialysis

\begin{tabular}{ll}
\hline Blood pressure (BP) medication & $N=160$ \\
\hline Calcium Channel blocker & 110 \\
Amlodipine & 56 \\
Nifedipine & 54 \\
Beta blockers & 58 \\
Angiotensin Converting Enzyme Inhibitor & 51 \\
Angiotensin Receptor Blocker & 46 \\
Diuretics & 40 \\
Avoid BP medications prior to hemodialysis & 107 \\
to allow for ultrafiltration & \\
\hline$B P=$ blood pressure &
\end{tabular}

\section{Timing of medication}

Most of the respondents 68\% (109/160) changed the dose of BP medications after the initiation of HD. In addition, 67\% (107/160) of the respondents reported asking patients not to take their BP medications on the morning of HD to allow for greater ultrafiltration. When asked about details regarding the dose adjustments of the BP medications on a daily basis, $41 \%(66 / 160)$ of the respondents were more likely to tell the patients to take the BP medications daily and 41\% (66/160) were more likely to tell the patient to take them on non-dialysis days only. Most of the respondents 58\% (93/160) would not tell their newly started HD patients to stop the BP medications completely.

Regarding discontinuation of anti-hypertensive medications, in choosing between beta blockers and calcium channel blockers, $72 \%$ (115/160) would first stop calcium channel blockers. As far as medications being dialyzed out, $68 \%(109 / 160)$ or respondents would not change beta blockers to those were not dialyzed. After starting dialysis, most responders $69 \%(110 / 160)$ reported they had patients on once a day or long acting calcium channel blockers.

\section{First month of dialysis and changes}

Ninety two percent of survey participants (147/160) replied that they would use a low blood flow setting (less than $300 \mathrm{ml} /$ minute) for the first dialysis session and $48 \%(77 / 160)$ would use a smaller than usual dialyzer,

Table 3 Use of Angiotensin Converting Enzyme Inhibitors and Angiotensin Receptor Blockers in Hemodialysis

\begin{tabular}{ll}
\hline Responses about ACEI and ARB on hemodialysis & $N=160$ \\
\hline Report that between 30 and 60\% of patients on ACEI or ARB & 82 \\
CKD5 would not stop ACE I or ARB & 98 \\
Would not change ACEl to one that is not dialyzed out & 123 \\
Would not stop ACEl or ARB despite hyperkalemia & 104 \\
\hline
\end{tabular}


while 94\% (150/160) prescribed less time for the first session. In addition, 64\% (102/160) would use a lower than usual dialysate flow rate. In general, 79\% (126/160) of respondents would dialyze the patient for less than a full dialysis session at the first session (Table 4).

In the first month of chronic dialysis, a large part of those surveyed, $88 \%(141 / 160)$, felt that ultrafiltration alone would help control BP and they would not use additional medications to the existing regiment. Fifty three percent $(85 / 160)$ of responders would set the dry weight in the first month, 29\% (46/160) in the first week and about $18 \%(29 / 160)$ would set the dry weight on the first day and adjust as needed.

Medication review was done one every month by the greater part of the participants $78 \%$ (125/160), every week by $12 \%(19 / 160)$ and as needed only by few $9 \%(15 / 160)$.

One option in non-adherent patients is to administer medications in dialysis. The larger part of those surveyed $85 \%(136 / 160)$ would not use BP medications while their patients were in $\mathrm{HD}$ even in the setting of non-adherence.

\section{Access use in early dialysis}

In response to the time interval between access creation and maturation, $53 \%(85 / 160)$ of responders felt it was usually between 6 and 12 weeks, 34\% (54/160) found it to be more than 12 weeks and $13 \%(21 / 160)$ noted that accesses would mature in less than 6 weeks. The question of how many angioplasties were considered to be acceptable before creating a new access had a distribution of responses: $27 \%$ (43/160) thought 3 angioplasties should be the most allowed, 25\% (40/160) replied 2, 23\% (37/160) replied more than $4,18 \%(29 / 160)$ replied that only one angioplasty should be done before a new access was needed and $7 \%(11 / 160)$ thought 4 could be acceptable before primary access failure needing the creation of a new access. Forty two percent $(67 / 160)$ of nephrologists responding to the survey felt that $30-60 \%$ of patients started HD with a permanent access in place, 31\% (50/160)

Table 4 Decision and changes made once hemodialysis was started

\begin{tabular}{ll}
\hline Decisions and changes made once HD started & $N=160$ \\
\hline Less than usual time for first HD & 150 \\
Lower than usual blood flow for first dialysis & 147 \\
$\begin{array}{l}\text { First anti-HTN medication to be stopped: calcium } \\
\text { channel blocker }\end{array}$ & 115 \\
Changed BP medication or doses once HD started & 109 \\
Continued use of diuretics in HD daily & 74 \\
Continued use of daily anti-hypertensives & 66 \\
Medication review done every month & 125 \\
Selected choice that HTN in HD is caused by multiple factors & 94 \\
\hline
\end{tabular}

$H D=$ hemodialysis,$A C E I=$ Angiotensin Converting Enzyme

Inhibitors, $H T N=$ hypertension felt it was between 10 and 30\% that started HD with a permanent access and 21\% (34/160) replied that it was more than $60 \%$ of HD patients that started HD with the required access. Nine responders avoided this question.

\section{Other renal replacement therapy options}

In the process of transitioning patients and other options being considered $44 \%(70 / 160)$ of responders felt that more than $50 \%$ of their incident HD patients who were eligible for transplant were listed for kidney transplantation. Eight percent of nephrologist who replied to the survey noted than $<10 \%$ of their CKD patients got a pre-emptive kidney transplantation. Asked about peritoneal dialysis (PD) as the first choice in those who were eligible, $44 \%(70 / 160)$ of respondents felt that only $10-50 \%$ started with their first choice even eligible to do so. The majority $65 \%(104 / 160)$ replied they had access to a patient educator.

\section{Discussion}

The first 90 days after starting HD is a period of high mortality with CVD as the leading cause of death. Hypertension, left ventricular hypertrophy, electrolyte and electrocardiographic abnormalities in dialysis are known to be contribute to the high mortality in this population [24-28]. The transition period has changes in these risk factors notably: BP, electrolytes, ultrafiltration and medications. The gap in knowledge about optimal BP control in HD in the new HD patient makes clinical care complex during this period. As there is no unified approach for BP control in new HD patients this survey of practicing nephrologists to determine common practices is relevant.

The survey found the most effective medication in HD for BP control to be calcium channel blockers, followed by beta blockers, based on studies showing benefits of these agents in selected dialysis populations [29-32]. The effectiveness of calcium channel blocker in HD may be partly explained by the observation that the high inflow of calcium from the dialysate into the blood stream during HD may increase BP and would suggest that blocking the vascular smooth muscle would help better control BP [33].

The increasing use of ACE I and beta blockers in dialysis patients with comorbid conditions like congestive heart failure and the benefits thereof were noted in the literature and was reflected in the common use of these medications in this study [34]. For example studies of USRDS data noted that beta blockers use had increased $75 \%$ in those with previous acute myocardial infarctions and ACEI and ARB use had increased in those with CHF $[35,36]$. In the survey, once on HD, the majority did not change ACEI (like enalapril, one third of which is dialyzed out) to one that would not be removed by dialysis, despite existing 
guidelines to do so. Most patients were instructed to avoid BP medications on HD days to allow for ultrafiltration- a common practice in HD, which is the opposite of recommendations that suggest daily nocturnal dosing of anti-hypertensive medications [37]. Avoidance of BP medications on HD days is not supported by literature; in one study of intra-dialytic BP variation it was noted that ultrafiltration volume resulted in greater change in systolic BP while the amount of anti-hypertensives was not associated with systolic BP changes [38]. A balanced option to minimize the risk of hypotension and cramping with HD while controlling BP is to keep patients on once a day nocturnal BP medications [39].

Responders noted that on HD initiation, anti-hypertensive medications were routinely changed, however uncertainty about BP fluctuations in the first month resulted in $88 \%$ using ultrafiltration alone to control BP without adding further medications. As dialysis vintage progressed there was a greater degree of comfort using anti-HTN medications.

The study found a majority of nephrologists prescribed diuretics in CKD 5 prior to HD but once HD was started less than half continued diuretics on a daily basis. In HD there is some benefit from diuretics; the underutilization noted in our study is consistent with known literature, possibly due to misperceived marginal benefits of the diuretics and possibly an attempt to lower the pill burden in new dialysis patients [40]. Further, with decreasing residual renal function, the effectiveness of diuretics decreases, while the risk of adverse drug events continues to be present. A practice of twice a week hemodialysis supplemented with diuretics may be of special benefit in the elderly with limited mobility to get to the HD unit. A recent study suggests that lower ultrafiltration in combination with a large dose diuretic use may help slow the decline in endogenous renal function for the first two years after dialysis initiation [41]. The majority of respondents felt that multiple causes lead to HTN in HD not just increased volume. Medication review was reported to be done monthly by the majority of nephrologists.

Volume appears to significantly contribute to HTN in HD and subsequently contribute to CVD mortality [19, 42, 43]. In the survey, nephrologists reported that dry weight was determined by between the first week and the first month. To combat inter-dialytic fluid gains, most ultrafiltration goals are determined clinically; only a minority of HD centers use bio-impedance routinely to determine fluid status according to a recent United Kingdom survey [44].

Most nephrologists would prescribe small dialyzers with a shorter period of time for the first dialysis session. The responses to questions about timing of access placement, maturity and salvage revealed the large majority considered access placement maturity needing at least 3 months, however the number of angioplasties to salvage the fistula showed a wide variation. Starting chronic dialysis is a major life sty le change for patients with many aspects that need improvement [45]. The presence of a dedicated dialysis educator may help make this transition smoother and $65 \%$ of the responders noted that their dialysis unit had an educator in their unit.

The limitations of our study includes the emphasis on the CVD risk in the transition period, while parameters like nutrition and phosphate control were not included [46]. The other limitation was the low response rate, but this similar to other nephrology studies in this group [47, 48]. As there is limited data about how nephrologists transition patients to dialysis, even with the above limitations, this study is helpful.

\section{Conclusion}

In summary, transitioning patients from CKD5 to HD continues to remain challenging in terms of mortality, BP control, medication use, medication reconciliation and the time to determine initial dry weight of the patient. There is a lack of consistent patterns in how patients are transitioned from CKD5 to HD, which may be expected in the absence of strong data. Clinical trials are needed to help transitioning patients from CKD 5 to HD to help improve patient outcomes.

\section{Additional file}

Additional file 1: Survey sample: transitioning patients from CKD to dialysis. (DOCX $16 \mathrm{~kb}$ )

\section{Abbreviations}

ACEl: Angiotensin converting enzyme inhibitor; ARB: Angiotensin receptor blocker; BP: Blood pressure; CKD: Chronic kidney disease; CKD5 D: Chronic kidney disease on dialysis; CKD5: Chronic kidney disease stage 5; CVD: Cardio-vascular disease; eGFR: Estimated glomerular filtration rate; ESRD: End-stage renal disease; HD: Hemodialysis; NKF: National Kidney Foundation; USRDS: United States Renal Data System

\section{Acknowledgements}

The authors would like to thank Ellen Yoshiuchi at the National Kidney Foundation for her help with survey distribution and Jacob A. Sabu for constructive criticism of the manuscript.

\section{Disclosure}

Financial disclosures- MCM-none, SF-none, RW-none, EL-none, AR-none, MS-none.

\section{Authors' contributions}

MCM,SF, RW, MS created the questions for the survey, MCM, AR, EL, MS analyzed and interpreted the data, MCM, AR and MS were major contributors in writing the manuscript. All authors read and approved the final manuscript.

Ethics approval and consent to participate

This study was approved by the Institutional Review Board.

Consent for publication

All authors consent for publication.

Competing interests

The authors declare that they have no competing interests. 


\section{Publisher's Note}

Springer Nature remains neutral with regard to jurisdictional claims in published maps and institutional affiliations.

\section{Author details}

'Division of Nephrology, State University of New York at Downstate, 450 Clarkson Avenue, Box 52, Brooklyn, New York 11203, USA. ² Division of Nephrology, Hofstra Northwell School of Medicine, Manhasset, USA. ${ }^{3}$ Division of Nephrology, University of Illinois at Chicago, Chicago, USA.

Received: 6 December 2017 Accepted: 7 June 2018

Published online: 22 June 2018

\section{References}

1. United States Renal Data System Annual Data Report. 2015 Volume 2: ESRD in the United States. Bethesda MD: National Institutes of Health, National Institute of Diabetes and Digestive and Kidney Diseases; 2015.

2. Broers NJ, Cuijpers AC, van der Sande FM, et al. The first year on haemodialysis: a critical transition. Clin Kidney J. 2015:8(3):271-7.

3. Bradbury B, Fissell R, Albert J, et al. Predictors of early mortality among incident US hemodialysis patients in the Dialysis outcomes and practice patterns study (DOPPS). Clin J Am Soc Nephrol. 2007;2(1):89-99.

4. A Randomized Trial of Intensive versus Standard Blood-Pressure Control. SPRINT research group, Wright JT Jr, Williamson JD, Whelton PK, et al. N Engl J Med. 2015;373(22):2103-16

5. Gul A, Miskulin D, Gassman J, et al. Design of the Blood Pressure Goals in Dialysis pilot study. Am J Med Sci. 2014;347(2):125-30.

6. Li Z, Lacson E Jr, Lowrie EG, et al. The epidemiology of systolic blood pressure and death risk in hemodialysis patients. Am J Kidney Dis. 2006;48:606-15.

7. Agarwal R, Nissenson AR, Batlle D, et al. Prevalence, treatment, and control of hypertension in chronic hemodialysis patients in the United States. Am J Med. 2003;115(4):291-7.

8. Port FK, Hulbert-Shearon TE, Wolfe RA, et al. Pre-dialysis blood pressure and mortality risk in a national sample of maintenance hemodialysis patients. Am J Kidney Dis. 1999;33:507-17.

9. Charra B, Terrat JC, Vanel T, et al. Long thrice weekly hemodialysis: the Tassin experience. Int J Artif Organs. 2004:27(4):265-83.

10. D'Amico M, Locatelli F. Hypertension in dialysis: pathophysiology and treatment. J Nephrol. 2002;15(4):438-45.

11. Ozkahya M, OkE, Toz H, et al. Long-term survival rates in hemodialysis patients treated with strict volume control. Nephrol Dial Transplant. 2006:21:3506-13.

12. Agarwal R, Alborzi $P$, Satyan $S$, et al. Dry-weight reduction in hypertensive hemodialysis patients (DRIP): a randomized, controlled trial. Hypertension. 2009:53(3):500-7.

13. Bragg-Gresham JL, Fissell RB, Mason NA, et al. Diuretic use, residual renal function, and mortality among hemodialysis patients in the Dialysis outcomes and practice pattern study (DOPPS). Am J Kidney Dis. 2007;49(3):426-31.

14. Zannad F, Kessler M, Lehert $P$, Grünfeld JP, Thuilliez C, Leizorovicz A, Lechat $P$. Prevention of cardiovascular events in end-stage renal disease: results of a randomized trial of fosinopril and implications for future studies. Kidney Int. 2006;70(7):1318-24

15. Zwiech R, Bruzda-Zwiech A. The dual blockade of the renin-angiotensin system in hemodialysis patients requires decreased dialysate sodium concentration. Int Urol Nephrol. 2013;45(5):1365-72.

16. Han SW, Won YW, Yi JH, et al. No impact of hyperkalaemia with reninangiotensin system blockades in maintenance haemodialysis patients. Nephrol Dial Transplant. 2007;22(4):1150-5.

17. Knoll GA, Sahgal A, Nair RC, et al. Renin-angiotensin system blockade and the risk of hyperkalemia in chronic hemodialysis patients. Am J Med. 2002; 112(2):110-4.

18. Chang $T$, Zheng $Y$, Montez-Rath $M$, et al. Antihypertensive medication use in older patients transitioning from chronic kidney disease to end-stage renal disease on Dialysis. Clin J Am Soc Nephrol. 2016;11(8):1401-12.

19. Jaeger JQ, Mehta RL. Assessment of dry weight in hemodialysis: an overview. J Am Soc Nephrol. 1999;10(2):392-403.

20. Okada K, Abe M, Takashima H, et al. Randomized trial of frequent lowefficiency and short hemodialysis/hemofiltration in hemodialysis patients with acute brain injury. Int J Artif Organs. 2013:36(11):793-802

21. Arieff Al, Massry SG, Barrientos A, et al. Brain water and electrolyte metabolism in uremia: effects of slow and rapid hemodialysis. Kidney Int. 1973;4(3):177-87.
22. Daugirdas J, Blake P. Ing. Handbook of Dialysis. Boston: T. Little Brown; 1994 p. 78-91.

23. Koyner JL, Cerdá J, Goldstein SL, et al. Acute kidney injury advisory Group of the American Society of nephrology. The daily burden of acute kidney injury: a survey of U.S. nephrologists on world kidney day. Am J Kidney Dis. 2014;64(3):394-401.

24. Harnett JD, Kent GM, Barre PE, Taylor R, Parfrey PS. Risk factors for the development of left ventricular hypertrophy in a prospectively followed cohort of dialysis patients. J Am Soc Nephrol. 1994;4(7):1486.

25. Parfrey PS, Foley RN, Harnett JD, Ke nt GM, Murray DC, Barre PE. Outcome and risk factors for left ventricular disorders in chronic uraemia. Nephrol Dial Transplant. 1996;11(7):1277.

26. Paoletti E, Specchia C, Di Maio G, Bellino D, Damasio B, Cassottana P, Cannella G. The worsening of left ventricular hypertrophy is the strongest predictor of sudden cardiac death in haemodialysis patients: a 10 year survey. Nephrol Dial Transplant. 2004;19(7):1829.

27. Stewart GA, Gansevoort RT, Mark PB, Rooney E, McDonagh TA, Dargie HJ, Stuart R, Rodger C, Jardine AG. Electrocardiographic abnormalities and uremic cardiomyopathy. Kidney Int. 2005;67(1):217.

28. Jadoul M, Thumma J, Fuller DS, Tentori F, Li Y, Morgenstern H, Mendelssohn D, Tomo T, Ethier J, Port F, Robinson BM. Modifiable practices associated with sudden death among hemodialysis patients in the Dialysis outcomes and practice patterns study. Clin J Am Soc Nephrol. 2012;7(5):765.

29. Abbott KC, Trespalacios FC, Agodoa LY, Taylor AJ, Bakris GL. Beta-blocker use in long-term dialysis patients: association with hospitalized heart failure and mortality. Arch Intern Med. 2004;164:2465-71.

30. Foley RN, Herzog CA, Collins AJ. Blood pressure and long-term mortality in US hemodialysis patients: USRDS waves 3 and 4 study. Kidney Int. 2002;62:1784-90.

31. Tepel M, Giet MV, Park A, Zidek W. Association of calcium channel blockers and mortality in haemodialysis patients. Clin Sci (Lond). 2002;103:511-5.

32. Kestenbaum B, Gillen DL, Sherrard DJ, Seliger S, Ball A, Stehman-Breen C. Calcium channel blocker use and mortality among patients with end-stage renal disease. Kidney Int. 2002;61:2157-64.

33. van Kuijk WH, Mulder AW, Peels CH, Harff GA, et al. Influence of changes in ionized calcium on cardiovascular reactivity during hemodialysis. Clin Nephrol. 1997;47(3):190-6.

34. Efrati S, Zaidenstein R, Dishy V, Beberashvili I, Sharist M, Averbukh Z, Golik A, Weissgarten J. ACE inhibitors and survival of hemodialysis patients. Am J Kidney Dis. 2002;40(5):1023.

35. United States Renal Data System. Annual Data Report: 2013 Volume 2: Atlas of Chronic Kidney Disease and End Stage Renal disease in the United States. National Institutes of Health, National Institute of Diabetes and Digestive and Kidney Disease. USA: Bethesda, MD; 2013.

36. Shafi T, Sozio SM, Luly J, et al. DEcIDE Network Patient Outcomes in End Stage Renal Disease Study Investigators. Antihypertensive medications and risk of death and hospitalizations in US hemodialysis patients: Evidence from a cohort study to inform hypertension treatment practices. Medicine. 2017:96(5):e5924. https://doi.org/10.1097/MD.0000000000005924.

37. K/DOQI clinical practice guidelines for cardiovascular disease in dialysis patients. K/DOQI workgroup. Am J Kidney Dis. 2005:45(4 Suppl 3):S1-153.

38. Flythe JE, Kunaparaju S, Dinesh K, et al. SM. Factors associated with intradialytic systolic blood pressure variability. Am J Kidney Dis. 2012;59(3):409-18.

39. Inrig JK. Antihypertensive agents in hemodialysis patients: a current perspective. Semin Dial. 2010;23(3):290-7.

40. Kumra R, Bargman JM. A review of diuretic use in dialysis patients. Adv Perit Dial. 2014;30:115-9.

41. Sjolund J, Garcia Anton D, Bayes LY, et al. Diuretics, limited ultrafiltration, and residual renal function in incident hemodialysis patients: a case series. Semin Dial. 2016;29(5):410-5.

42. Charra B, Calemard E, Cuche M, et al. Control of hypertension and prolonged survival on maintenance hemodialysis. Nephron. 1983;33(2):96-9.

43. Fishbane S, Natke E, Maesaka JK. Role of volume overload in dialysisrefractory hypertension. Am J Kidney Dis. 1996;28(2):257-61.

44. Dasgupta I, Farrington K, Davies SJ, et al. UK National Survey of practice patterns of fluid volume Management in Haemodialysis Patients: a need for evidence. Blood Purif. 2016;41(4):324-31.

45. Moist LM, Lok CE. Incident Dialysis access in patients with end-stage kidney disease: what needs to be improved. Semin Nephrol. 2017;37(2):151-8.

46. Broers NJ, Cuijpers AC, van der Sande FM, Leunissen KM, Kooman JP. The first year on haemodialysis: a critical transition. Clin Kidney J. 2015;8(3):271-7. 
47. van de Luijtgaarden MW, Noordzij M, Tomson C, et al. Factors influencing the decision to start renal replacement therapy: results of a survey among European nephrologists. Am J Kidney Dis. 2012;60(6):940-8.

48. Mallappallil MC, Mehta R, Yoshiuchi E, et al. M. Parameters used to discontinue dialysis in acute kidney injury recovery: a survey of United States nephrologists. Nephron. 2015;130(1):41-7.

Ready to submit your research? Choose BMC and benefit from:

- fast, convenient online submission

- thorough peer review by experienced researchers in your field

- rapid publication on acceptance

- support for research data, including large and complex data types

- gold Open Access which fosters wider collaboration and increased citations

- maximum visibility for your research: over $100 \mathrm{M}$ website views per year 